\title{
A roadmap for smart city services to address challenges faced by small businesses in South Africa
}

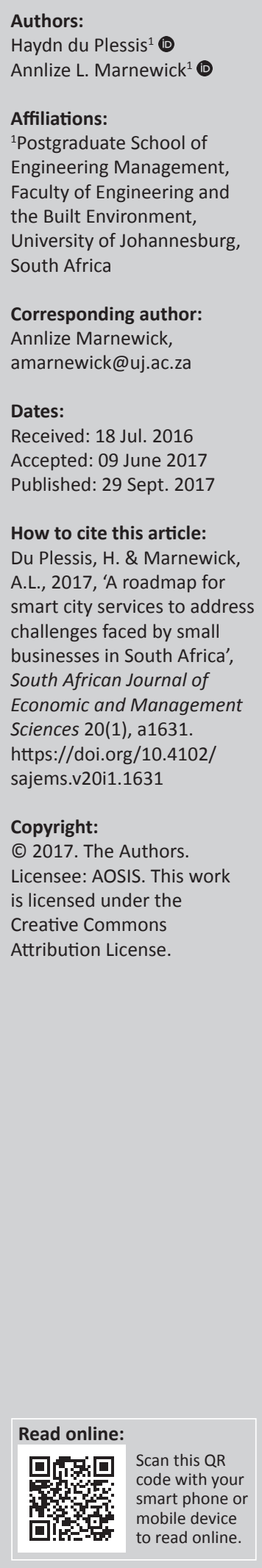

Background: Small businesses are an important part of the South African economy, yet they have high rates of failure. Several contributing factors have previously been identified through literature, including regulatory compliance, skills shortages and lack of government support. Globally, there has been an increased interest in smart cities and the variety of services they offer. These technologies were investigated to establish what role, if any, they could play in alleviating the challenges that small businesses face.

Aim: Identify the relative impact of each of these challenges on the small-business and the relative value of each of the smart city services in order to determine which services would have the largest impact in addressing the challenges.

Method: This research used these factors and identified which challenges had the largest time and financial impact on small businesses and investigated ways in which a variety of smart city services could be leveraged to address these challenges. Using a multi-criteria decision analysis technique, 44 small-business owners participated in the research. Weighted results for the impact of each of the challenges and the value of each of the services were obtained.

Results: Through the subsequent analysis of the results, it was found that small businesses face many challenges because of lack of government and entrepreneurial support, as well as widespread corruption. Similarly, the small-business owners identified that educational material, small-business support portals and eGovernment systems would be the most valuable services that a smart city could offer them. Various sources of literature were used to identify these smart city services and link them to the business challenges that they may be able to mitigate. The infrastructural prerequisites for each of the services were also investigated to identify dependencies and potential problems in their deployment.

Conclusion: The various aspects of this study were integrated, and a smart city roadmap for small-business support was subsequently developed. This roadmap will assist cities in planning their smart city deployment, so that they may better support small businesses in the role that they play in the country's economy.

\section{Introduction}

In South Africa, SBP (2014) and Olawale and Garwe (2010) found that small businesses are responsible for $56 \%-60 \%$ of the country's employment, which leaves considerable ground to be covered in order to meet the National Development Plan's target of $90 \%$ set by the National Planning Commission (2010). By contrast, in New Zealand, which is considered the easiest country in which to start a business (World Bank Group 2014), the New Zealand Government (2015) found that $97 \%$ of their population is employed by small and medium enterprises (SMEs).

Businesses face a variety of challenges which could prevent them from reaching their full potential; one such challenge is maintaining regulatory compliance, which SBP (2014) has identified as the most critical challenge facing South African SMEs. SBP (2004) has determined that on average it takes eight working days per annum to maintain regulatory compliance, largely because of overlapping, conflicting and ever-changing regulations, lack of information access, as well as inefficiencies within the various municipalities themselves.

Groepe (2012) emphasises that small businesses have a crucial role to play within the economy, and as such, steps should be taken to alleviate the challenges they face, so that they may become more effective contributors to the economy. Herrington, Kew and Kew (2014) note that this can be accomplished through an increased focus on education and skills and by creating a more enabling entrepreneurial environment. For example, online Web portals can be utilised to reduce regulatory red tape, making it easier to start a new business. 
The usage of online portals and eGovernment services is one of the core services in the emergence of smart cities, as found by Albino, Berardi and Dangelico (2015), Calzada and Cobo (2015) and Lövehagen and Bondesson (2013). According to the United Nations (2014), this improved accessibility can make it easier for small businesses to conduct their daily operations by removing the physical barriers associated with typical municipal interactions and by allowing them to operate in a more autonomous and self-sufficient manner.

Businesses face several challenges on an ongoing basis, and the types of challenges are expected to vary depending on the nature of the business. To identify which smart city services should be prioritised, the objective of this research was first to determine which challenges have the greatest impact on small businesses. Literature was then used to select smart city services that have the potential to address these challenges.

A total of 44 small-business owners from various sectors participated in this research by completing an online survey. A multi-criteria decision-making framework was then used to rank the challenges faced in terms of their impact on the business. Similarly, the potential smart city services were ranked in terms of the value that they could offer the businesses.

Once the prioritised challenges and services had been determined, the infrastructural and technological prerequisites of each of the proposed smart city services were investigated. This allowed dependencies to be identified so that a logical service deployment could be achieved. These results were subsequently integrated into a technology roadmap that can assist cities in planning for their own smart city rollouts.

\section{Research questions}

The purpose of this research was to explore the challenges that South African small businesses face so that suitable smart city services can be identified to alleviate these challenges. These services will have several infrastructural prerequisites that must be met before they can be deployed, and recommendations are made on how these services should be developed.

To achieve this, the following research questions were formulated:

- What challenges are South African small businesses faced with?

- Which smart city services would offer the most value to these small businesses?

- What development roadmap should be followed to ensure that these services are implemented successfully?

When planning any smart city deployment, there are many stakeholders that need to be considered, including businesses, communities and schools. This research was limited to assessing value from the perspective of small businesses only.

\section{Literature survey Definitions}

There are numerous definitions of a smart city, as discussed by Albino et al. (2015). For the purposes of this research, the definition by Caragliu, Del Bo and Nijkamp (2011) was adopted:

a city is considered to be smart when investments in human and social capital and traditional (transport) and modern (ICT) communication infrastructure fuel sustainable economic growth and a high quality of life, with a wise management of natural resources, through participatory governance. (p. 70)

This research dealt with the challenges that small businesses face as well as smart cities and the services they offer. For brevity, some aspects are grouped into generic terms, with the full definitions being available in Appendix 1.

\section{Small-business challenges}

Worldwide, small businesses employ an average of $77 \%$ of the population, yet this is not the case in South Africa. Research by SBP (2014) has shown this figure to be closer to $60 \%$. Additionally, small businesses have high failure rates, with Zulu (2015) claiming that as few as $9 \%$ of businesses remain operational after 10 years. These businesses face various challenges on a regular basis which, if addressed, could pave the way for them to become more significant contributors to the economy.

Examining the literature reveals that many prominent challenges facing businesses have been identified, such as maintaining regulatory compliance, dealing with corruption, skills shortages and infrastructure issues. These challenges have been grouped in Table 1, as per the definitions in Appendix 1. For each item in Table 1, various sources of literature were used to establish each challenge as being a viable threat to small businesses.

One of the most commonly recurring challenges is the lack of entrepreneurial training and education, which was identified by each of the sources in Table 1. Typically, this includes general aspects of business operations and management, but Worku (2016) found that this demand exists even at school level and suggests that governments consider offering entrepreneurial training to interested candidates immediately after leaving school.

Access to finance is the largest obstacle to small-business growth, as identified by Olawale and Garwe (2010), with Worku (2016) finding that businesses need over R50 000 on average in initial capital in order to become viable. Although the government has made various funding bodies available to small businesses, Peters and Naicker (2013) maintain that many businesses are not even aware of all the avenues of funding available to them and that a significant number do not pursue these sources of funding because of the amount of bureaucracy and red tape involved. 
TABLE 1: Issues facing South African small businesses.

\begin{tabular}{|c|c|c|c|c|c|c|c|c|}
\hline $\begin{array}{l}\text { Small-business } \\
\text { challenges }\end{array}$ & $\begin{array}{l}\text { Examining the } \\
\text { challenges } \\
\text { facing small } \\
\text { businesses in } \\
\text { South Africa: } \\
\text { SBP (2014) }\end{array}$ & $\begin{array}{c}\text { The global } \\
\text { competitiveness } \\
\text { report } \\
\text { 2014-2105: } \\
\text { Schwab (2014) }\end{array}$ & $\begin{array}{c}\text { Global } \\
\text { entrepreneurship } \\
\text { monitor - South } \\
\text { African report } \\
\text { 2010: herrington, } \\
\text { Kew And Kew } \\
\text { (2010) }\end{array}$ & $\begin{array}{l}\text { Obstacles to the } \\
\text { growth of new } \\
\text { SMEs in South } \\
\text { Africa: Olawale } \\
\text { and Garwe } \\
\text { (2010) }\end{array}$ & $\begin{array}{l}\text { The small, medium } \\
\text { and micro- } \\
\text { enterprise sector } \\
\text { of South Africa: } \\
\text { SEDA (2016) }\end{array}$ & $\begin{array}{l}\text { Improving the } \\
\text { business } \\
\text { environment for } \\
\text { growth and job } \\
\text { creation in South } \\
\text { Africa: The World } \\
\text { Bank (2011) }\end{array}$ & $\begin{array}{c}\text { Barriers to the } \\
\text { growth of small, } \\
\text { micro and } \\
\text { medium-sized } \\
\text { business } \\
\text { enterprises [...]: } \\
\text { Worku (2016) }\end{array}$ & $\begin{array}{c}\text { Small, medium } \\
\text { micro-enterprise } \\
\text { business goals and } \\
\text { government support: } \\
\text { a South African case } \\
\text { study: Peters and } \\
\text { Naicker (2013) }\end{array}$ \\
\hline Government support & $\checkmark$ & $\checkmark$ & $\checkmark$ & $\checkmark$ & $\checkmark$ & $\checkmark$ & $\checkmark$ & - \\
\hline Entrepreneurial support & $\checkmark$ & $\checkmark$ & $\checkmark$ & $\checkmark$ & $\checkmark$ & $\checkmark$ & $\checkmark$ & $\checkmark$ \\
\hline Corruption & - & $\checkmark$ & $\checkmark$ & $\checkmark$ & - & $\checkmark$ & - & $\checkmark$ \\
\hline Infrastructural issues & - & $\checkmark$ & - & $\checkmark$ & $\checkmark$ & - & - & - \\
\hline Workforce issues & $\checkmark$ & $\checkmark$ & - & - & $\checkmark$ & $\checkmark$ & $\checkmark$ & - \\
\hline Regulatory compliance & $\checkmark$ & - & $\checkmark$ & $\checkmark$ & $\checkmark$ & $\checkmark$ & - & $\checkmark$ \\
\hline
\end{tabular}

SME, small and medium enterprise.

However, red tape is not only an issue in terms of inhibiting access to funding - red tape associated with maintaining regulatory compliance costs businesses an average of eight working days per year (SBP 2014).

Other sources of red tape include dealing with the South African Revenue Service, labour issues and black economic empowerment compliance (SBP 2014). This is further burdened by frequent changes in the regulatory environment, lack of access to information and various administrative inefficiencies. These issues were also identified by the World Economic Forum and the World Bank Group (Schwab 2014; The World Bank 2011), with the World Bank Group (2014) further finding that the use of electronic resources may be able to alleviate these issues.

The literature identifies corruption as being in the top $11 \%$ of the most problematic factors for doing business (Schwab 2014). Corruption is particularly prevalent when there is a lack of transparency and accountability, but Andersen (2009) asserts that the usage of online government systems reduces corruption because of its ability to reduce or remove contact between corrupt officials.

Although infrastructural and workforce issues are generally not considered to be as critical as the other challenges addressed here, they were identified by SEDA (2016) as key impediments because of the significant costs they add to doing business. Having access to efficient utilities and transport systems, along with access to affordable communication services and property, is instrumental in supporting new businesses (Herrington et al. 2014).

Subsequently, the literature reveals that many, if not all, of these issues could be alleviated through using various smart city services. This was explored further to identify which services hold the most potential to address these challenges, as well as identify any crucial prerequisites and interdependencies.

\section{Smart city services}

With the growing ubiquity of wireless networks, trends in connected services have begun to emerge, with the concept of smart cities also gaining interest. As discussed by Albino et al. (2015), Lövehagen and Bondesson (2013) and Calzada and Cobo (2015), a critical theme throughout smart city literature is the notion of leveraging digital systems and communications networks to improve efficiency, promote development and encourage sustainability.

However, these systems alone are not enough to make a city smart. Chourabi et al. (2012), Lee, Hancock and Hu (2014) and Woods and Goldstein (2014) describe the physical aspects of this infrastructure, the servers, storage and processing power that are required. These cities rely heavily on large volumes of data (Stratigea, Papadopoulou \& Panagiotopoulou 2015; Woods \& Goldstein 2014) in order to provide real-time insight into the cities' operations, thereby allowing them to improve efficiencies and identify emerging trends (Albino et al. 2015; Chourabi et al. 2012; Stratigea et al. 2015).

There are several such services that a city could deploy, and cities must work to ensure alignment between the stakeholders' expectations and what is offered. Proper adoption of these services may also require behavioural change within the various stakeholder groups (Branchi, Fernández-Valdivielso \& Matias 2014; Calzada \& Cobo 2015) and can be accomplished through the increased awareness of the benefits that the smart city has to offer.

Deploying Wi-Fi at city-wide level is a concept that is gaining in popularity and is often seen as a first step for a city to become smarter. Walravens (2015) explores how this can be used as the founding infrastructure for other initiatives but states that it is typically focused in more densely populated areas, which limits its usefulness. However, Lee et al. (2014) caution that being able to offer this service requires a significant investment in backhaul network connectivity, as well as the equipment required to operate the wireless network. Additionally, this is a time-consuming process and can be somewhat disruptive because of the construction that needs to take place.

Smart cities typically incorporate aspects of eGovernment and open data policies to provide a variety of services to stakeholders. In doing so, they can provide skills training, financial support as well as general information to interested parties. SBP (2014) and the United Nations (2014) describe how online access to smart portals can help combat governmental inefficiencies by removing the physical barriers associated with a business's interactions with the city. 
Although eGovernment does not require the vast physical infrastructure that a Wi-Fi rollout does, it still relies heavily on interconnectivity between departments, municipalities and third-party services. To ensure effective eGovernment implementation, the Hong Kong government (2016) and Ryan (2014) suggest that the network topology be carefully planned, while ensuring that security and access control are implemented through a combination of firewalls, encryption schemes and authentication systems.

Part of any smart city adoption is ensuring the use of the various services through the ongoing education of the communities; Stratigea et al. (2015) and Lövehagen and Bondesson (2013) caution that the failure to properly educate the stakeholders could lead to the lack of service adoption. However, apart from just imparting basic knowledge, smart cities have the potential to provide access to a variety of skills and educational training, such as finance and management two areas which could prove valuable to business owners.

Availability of educational content has additional benefits, as Dirks and Keeling (2009) and Letaifa (2015) have found. Increased educational levels are a major motivating factor for potential citizens, with educated workforces experiencing faster growth and subsequently being able to attract more graduates to the city, which in turn drives an increase in knowledge and innovation.

Because of the interaction that any potential smart city services will have with each other, it is crucial to plan their development so that efficient integration is ensured. This typically requires that services start off at a basic level and then slowly evolve to include more functionality and deeper integration with other aspects of the city, a process described by Kumar (2015). By adopting a more agile development approach, cities can constantly align their service offerings with the expectations of the stakeholders. Figure 1 shows a potential approach that was adapted from Birmingham's own smart city deployment (Kakderi 2014). This process allows incremental developments to be tested and guided by a small group of early adopters, before making that functionality available to the general population.

At the time of writing, the City of Johannesburg was in the process of rolling out some of its own smart city initiatives. This included the deployment of a widespread broadband fibre network throughout the city, with further plans to offer Wi-Fi connectivity in some areas (Templeton 2015). The city has also begun the process of making it possible to submit some regulatory documents online, in addition to partnering with educational institutions to provide access to selected online courses (Shezi 2015). To encourage collaboration between municipalities throughout the country, the city has made its smart city portal available to other municipalities (Burger 2015).

\section{Mapping challenges to services}

Having established the major challenges that small businesses face, the literature was used to link each challenge to a variety of smart city services that could potentially address the challenge. The sources for each of the statements below, along with a summary of this mapping, are provided in Table 2; it was found that focusing on a small selection of smart city
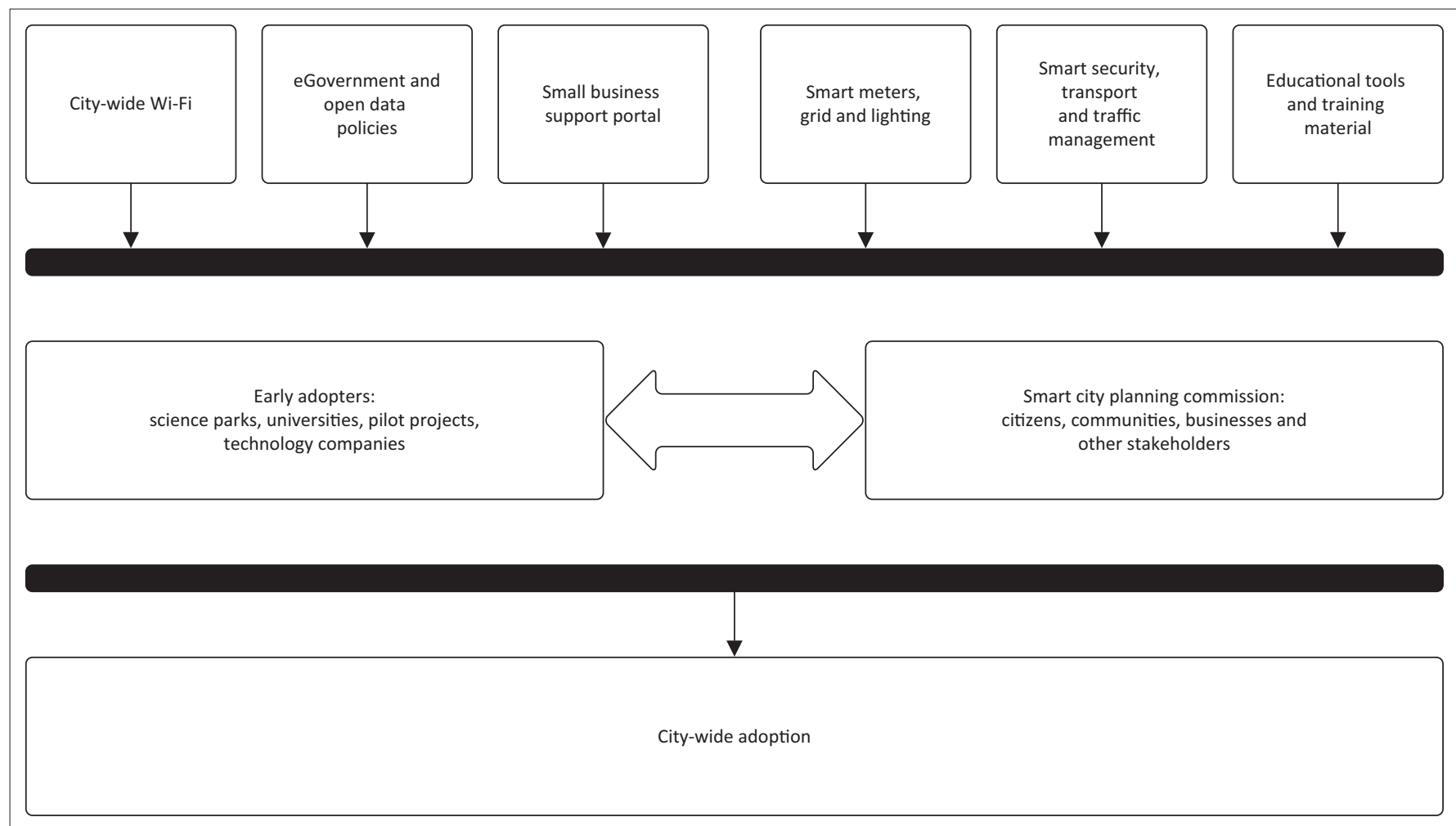

FIGURE 1: A potential smart city development process. 
TABLE 2: Mapping of small-business challenges to smart city services.

\begin{tabular}{|c|c|c|c|c|c|c|}
\hline \multirow[t]{2}{*}{ Smart city services } & \multicolumn{6}{|c|}{ Small-business challenges } \\
\hline & Government support & Entrepreneurial support & Corruption & Infrastructural issues & Workforce issues & Regulatory compliance \\
\hline $\begin{array}{l}\text { Educational tools and } \\
\text { training material }\end{array}$ & - & $\begin{array}{l}\text { Adisa, Abdulraheem and } \\
\text { Mordi (2014); } \\
\text { Kirkwood, Dwyer and } \\
\text { Gray (2014); } \\
\text { Wang and Wang (2015); } \\
\text { Worku (2016) }\end{array}$ & - & - & - & Wang and Wang (2015) \\
\hline $\begin{array}{l}\text { Small-business support } \\
\text { portal }\end{array}$ & $\begin{array}{l}\text { Chen, Jaw and Wu } \\
(2016) ; \\
\text { Lee }(2010)\end{array}$ & $\begin{array}{l}\text { Chen et al. (2016); } \\
\text { Lee (2010). }\end{array}$ & - & - & - & $\begin{array}{l}\text { Chen et al. (2016); } \\
\text { Lee (2010). }\end{array}$ \\
\hline $\begin{array}{l}\text { eGovernment and open } \\
\text { data policies }\end{array}$ & $\begin{array}{l}\text { Kuk and Janssen } \\
\text { (2011); } \\
\text { Walravens (2015) }\end{array}$ & $\begin{array}{l}\text { Kuk and Janssen (2011); } \\
\text { Lee et al. (2014); } \\
\text { Walravens (2015). }\end{array}$ & $\begin{array}{l}\text { Andersen (2009); } \\
\text { Lio, Liu and Ou (2011); } \\
\text { Neupane et al. (2014); } \\
\text { United Nations (2014). }\end{array}$ & $\begin{array}{l}\text { Lee et al. (2014); } \\
\text { United Nations (2014); } \\
\text { Walravens (2015). }\end{array}$ & $\begin{array}{l}\text { United Nations } \\
\text { (2014) }\end{array}$ & $\begin{array}{l}\text { Lee (2010); Kuk and } \\
\text { Janssen (2011); Lee } \\
\text { et al. (2014) }\end{array}$ \\
\hline City-wide Wi-Fi & - & $\begin{array}{l}\text { Albino et al. (2015); } \\
\text { Bătăgan (2011); } \\
\text { Letaifa (2015). }\end{array}$ & - & Lee et al. (2014). & - & - \\
\hline $\begin{array}{l}\text { Smart meters, grid and } \\
\text { lighting }\end{array}$ & - & $\begin{array}{l}\text { Bradley, Barbier and } \\
\text { Handler (2013) }\end{array}$ & - & $\begin{array}{l}\text { Adisa et al. (2014); } \\
\text { Bradley et al. (2013); } \\
\text { Lee et al. (2014). }\end{array}$ & - & - \\
\hline $\begin{array}{l}\text { Smart security, transport } \\
\text { and traffic management }\end{array}$ & - & $\begin{array}{l}\text { Dirks and Keeling (2009); } \\
\text { Lee, Phaal and Lee (2013) }\end{array}$ & $\begin{array}{l}\text { Dirks and Keeling } \\
\text { (2009) }\end{array}$ & $\begin{array}{l}\text { Calderoni, Maio and } \\
\text { Palmieri (2012); } \\
\text { Dirks and Keeling (2009); } \\
\text { Lee et al. (2013); Lee } \\
\text { et al. (2014) }\end{array}$ & - & - \\
\hline
\end{tabular}

services would result in an improvement across each of the identified challenges.

The value that eGovernment offers very quickly becomes clear, as the literature has shown that it is able to address each of the challenges to various extents. Furthermore, eGovernment is the only service capable of addressing workforce issues - a crucial consideration for South Africa's economy.

By combining eGovernment with other Web-based services, such as online portals and educational material, a city would be able to offer significant value from a centralised system. These three services, when combined and integrated, would form the foundation from which the other services could be monitored and managed. Additionally, because of the nature of centralised systems, cities would be able to constantly expand their service offerings, further increasing the value of these smart city services over time.

The remaining three services (city-wide Wi-Fi, smart traffic management and smart power) are all decentralised services, and they would predominantly contribute to addressing the infrastructural issues that pose a challenge to small businesses. However, because of their reliance on physical infrastructure, these services could be logistically more challenging to deploy.

Finally, only eGovernment and smart security services would able to address the issue of corruption that businesses face an important factor to mitigate because of the impact that it has on small businesses.

In concluding the literature review, it has been shown that small businesses face a variety of challenges that inhibit them from reaching their full potential. Furthermore, it was shown that certain smart city initiatives make it possible to alleviate, or even eliminate, these challenges that continue to plague small businesses in the country.

\section{Research design}

To answer the research questions, the relative impact and potential of small-business challenges and smart city services had to be determined. However, different businesses face differing challenges, and therefore, a single business case could not be used. An expert in the field of small-business challenges could be utilised to determine the relative importance of the issues faced. However, research by Castillo (2013) has shown that judgements made by a group of nonexperts are typically far more accurate than the judgement of a single expert. As such, this research sought to include the responses and feedback from a group of small-business owners.

\section{The analytical hierarchy process}

Analytical hierarchy process (AHP) was chosen as the decision-making framework because of its effectiveness as a collaborative group decision-making tool. When compared to other multi-criteria decision-making techniques, AHP was found by Peniwati (2007) to offer the most valid indication of a group decision and is most capable of resolving conflicts within a group decision.

As described by Saaty (1990), the tool's inventor, AHP is a hierarchical decision-making framework that is capable of incorporating both tangible and intangible aspects in the evaluation. This is accomplished by ranking the various alternatives, based on how well they meet a series of criteria that define the decision goal.

The tool also includes the ability to perform consistency checking to identify any potential issues within the results, while still being able to account for some degree of inconsistency because of differences in human judgement. As described by Saaty $(1987,2008)$, group decisions can be made by allowing individuals to complete their own decision matrices, and then calculating the geometric mean to yield 
the group decision matrix. AHP is well documented within the literature, but the process can be briefly summarised from Vaidya and Kumar (2006) as follows:

- identify the objective

- develop the hierarchical decision structure incorporating the goal, the criteria and the alternatives

- utilise pairwise comparisons to rank the alternatives

- perform consistency checks and reject inconsistent responses

- calculate the relative weightings of each of the criteria.

Brunelli (2015) found AHP to be an effective tool for city evaluation and planning and discusses how it can be used to determine which features and services consumers value most when purchasing smartphones and electronic devices. Further research by Vaidya and Kumar (2006) confirms that AHP is suitable for a wide variety of decision-making problems, largely as a result of its inherent flexibility and adaptability, making it a suitable framework to use when evaluating the challenges that small businesses face and how various smart city services could be used to alleviate them.

\section{Research methodology}

Having established a theoretical basis for this research through the literature and having identified AHP as a suitable decision-making framework, it was then necessary to develop the hierarchical decision structure required by AHP. This was accomplished through a series of informal interviews to validate the literature and provide additional context. Two executives from the Gauteng Department of Economic Development were interviewed to establish Gauteng's involvement in and plans for their own smart city deployment, with the intention being that this research could further supplement their own.

Several informal interviews were conducted with small businesses in the Johannesburg region, with the focus being on the challenges they face as well as how they believed these challenges could best be addressed. In most cases, these solutions were in line with the identified smart city services. For example, the businesses expressed a strong interest in being able to complete regulatory paperwork online or gain access to educational content - two factors that fall within the scope of the smart city services discussed in the literature.

Although informal, these discussions provided a good basis for the subsequent research by validating the challenges faced, as well as the potential solutions to these challenges. This also ensured that the challenges being faced by small businesses have remained relevant in the country's ever-changing political and regulatory environment. The development of the AHP decision structure is discussed further in the section 'Applying the analytical hierarchy process structure'.

To conduct this research, a standardised questionnaire was developed to allow participants to rank both the challenges they faced as well as the smart city services identified. By deriving the questionnaire from the AHP decision structure described in the section 'Applying the analytical hierarchy process structure', it would be possible to gain insight into the relative impact of each challenge or service. At this point, the questionnaire was tested with the AHP process to ensure that it could achieve the desired objective based on the required decision structure.

The questionnaire was then tested by two small-business owners to gather their feedback, thereby checking that the participants could understand the questionnaire and verifying that it took an acceptable amount of time to complete. Once the revisions were incorporated, the questionnaire was used to collect and subsequently analyse the data. Figure 2 summarises the research process that was described in this section, and then followed when developing the research tool and conducting the research.

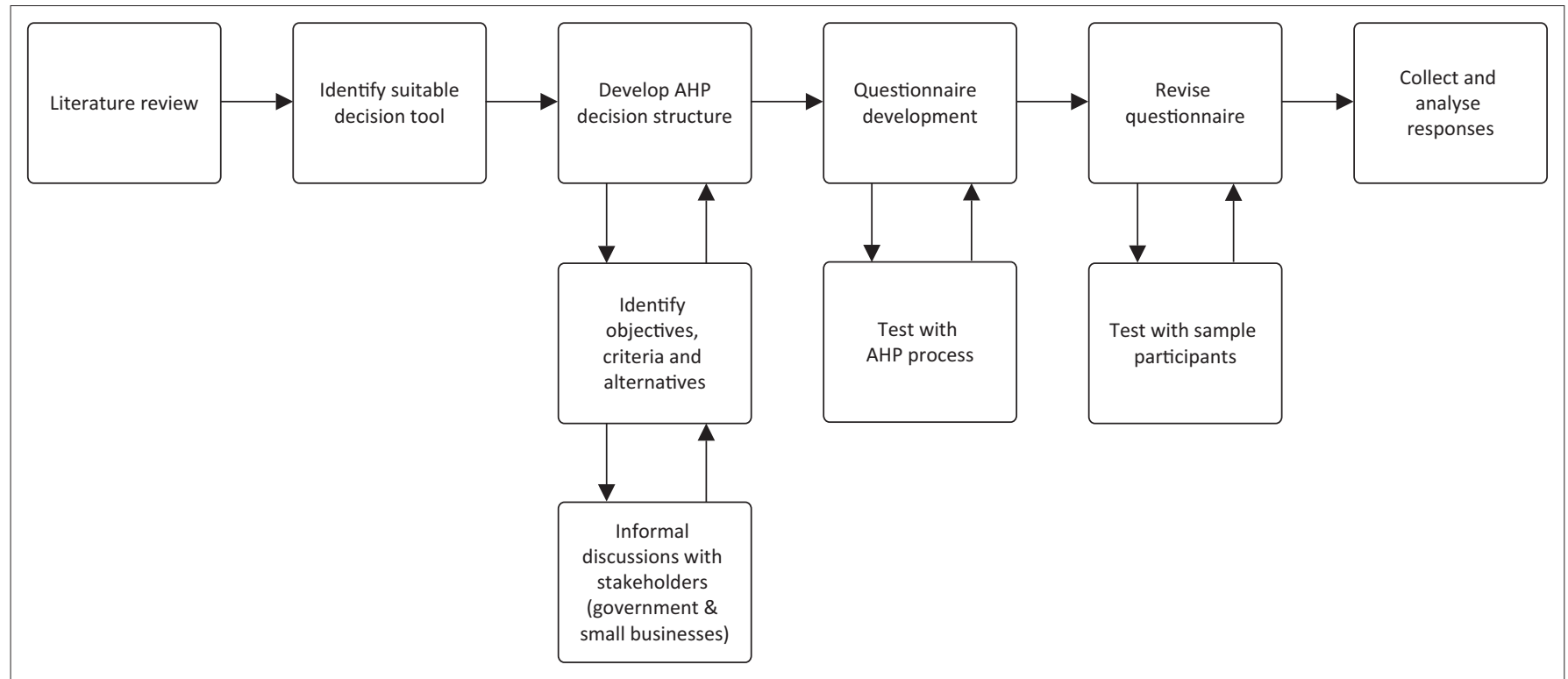

FIGURE 2: The research process. 


\section{Applying the analytical hierarchy process structure}

To develop the AHP decision structure, it is first necessary to identify the objectives, as described by the process outlined in section: 'The analytical hierarchy process'. For this research, there were two AHP objectives:

- determine the impact of the small-business challenges identified

- determine the value of the smart city services identified.

Next, it is necessary to identify the criteria to use when solving for the objective. As discussed by SBP (2014), the challenges that small businesses face impact them in two primary ways - time lost and cost incurred. Similarly, the value of the smart city services can be assessed in terms of the value they offer - both in time and costs saved as well as their importance in a smart city.

Based on Table 1 and the definitions in Appendix 1, the alternatives for the small-business challenges were identified as regulatory compliance, government support, infrastructural issues, entrepreneurial support, workforce issues and corruption. The resulting decision structure for determining the impact of the challenges that small-business face is shown in Figure 3.

Similarly, based on Table 2 and the definitions in Appendix 1, the alternatives for the smart city services were identified as city-wide Wi-Fi; eGovernment and open data policies; small-business support portal; smart meters, grid and lighting; smart security, transport and traffic management and educational tools and training material. The resulting decision structure for determining the value of smart city services is shown in Figure 4.

By developing two distinct decision structures, it was possible to verify the selected smart city services both through literature (from Table 2), as well as through the participants' own responses, thereby increasing the confidence that the correct services were identified.

\section{Data collection and analysis}

Using the derived AHP structure, an online survey was used to conduct the research. To complete the decision matrices, participants were guided through a series of multiple-choice questions to establish the relative importance of each alternative.

For the sampled participants to be representative of the small-business population, participation in the research was limited to individuals who owned or were involved in the management of small businesses that operated within South Africa. These businesses could operate within any industry sector and were considered small if they employed fewer than 50 people. This ensured that the research data were collected from participants who were qualified to provide insight into the challenges that small businesses face and which smart city services may be able to add value for them.

Because the entire population of South African small businesses was not known, the following businesses and

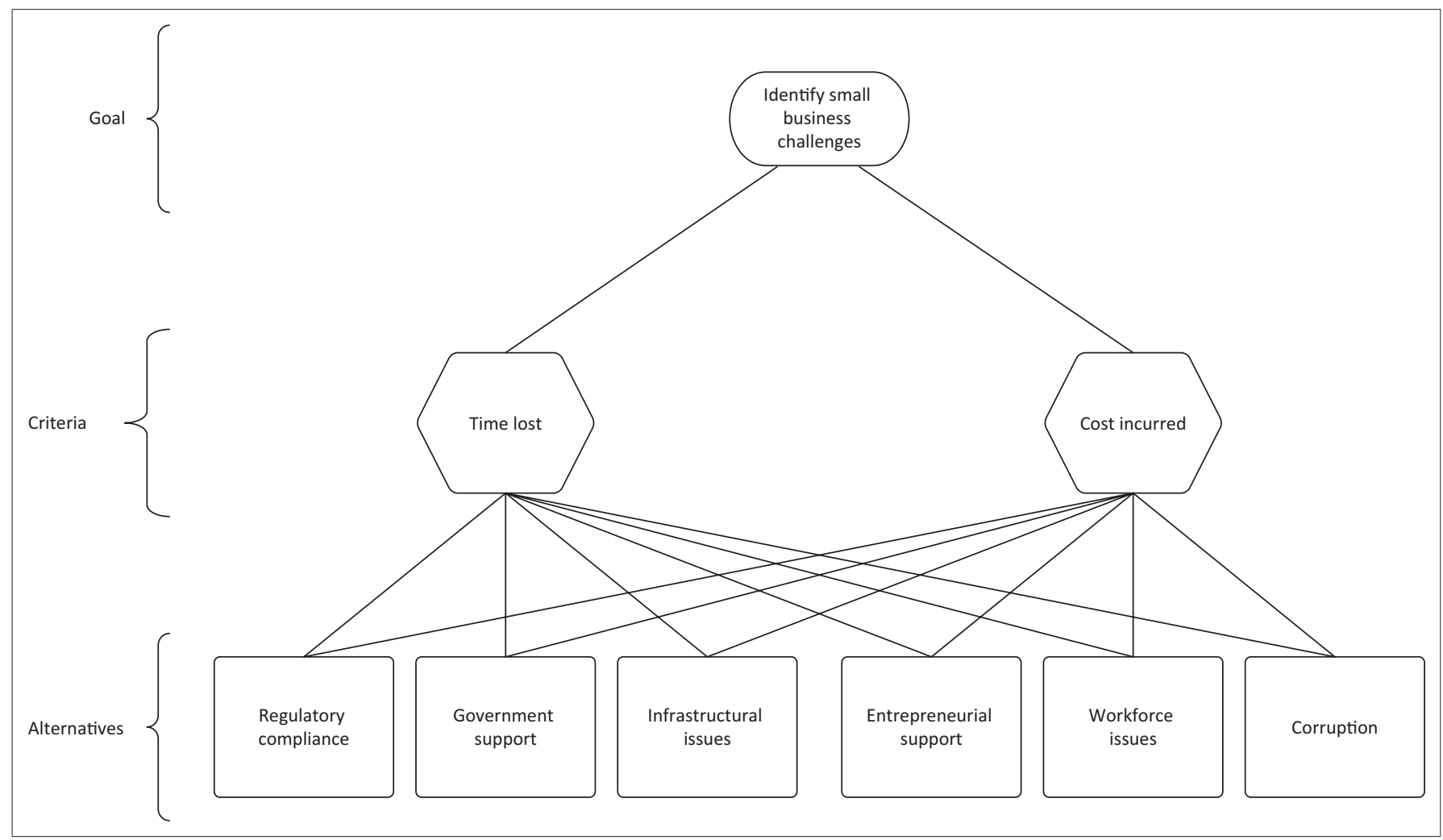

FIGURE 3: Analytical hierarchy process diagram for small-business challenges. 


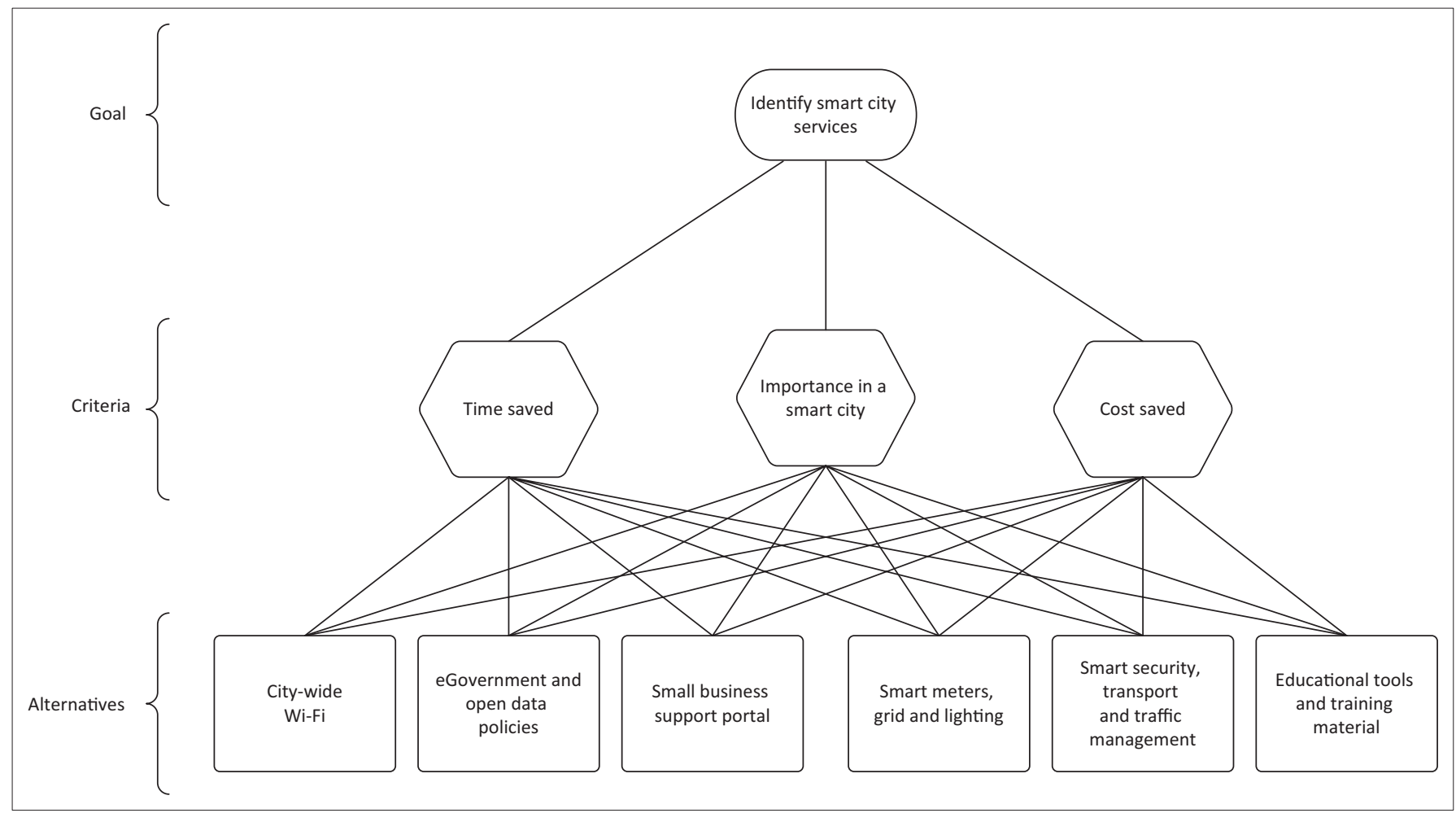

FIGURE 4: Analytical hierarchy process diagram of smart city services.

people were contacted directly, with snowball sampling being used subsequently to solicit additional responses:

- various consultants who regularly worked with small businesses (approximately 30 people)

- the recipients of the Radio 702 Small-Business Awards from 2009 to 2015 (approximately 250 people)

- some businesses that had worked with the Ministry of Small-Business Development (approximately 20 people).

The research was carried out using standardised, pretested and pre-validated questionnaires distributed through an online survey system to gather data from the sample of the small-business sector. Scales were utilised as the primary principle of measurement, making it possible to incorporate both the objective and subjective aspects of the decisionmaking process. By conducting the research in this way, it was possible to conduct a detailed analysis that would ensure that the most important challenges and services were identified.

The questionnaire consisted of four sections. The first section gathered demographic data to ensure that the participants fit the profile of a small-business. This section included questions relating to revenue, location, number of employees, business sector and other factors. The second section required participants to indicate the time and financial cost incurred in overcoming each of the challenges identified in Table 1. The final two sections required the participants to rank, using the AHP comparisons, the relative impact of each of the challenges and smart city services.

Of the approximately 300 people who were invited to participate, a total of 82 responses were recorded. However,
38 respondents started the survey but did not reach completion, and their results were subsequently discarded. This then left 44 valid responses.

The survey system was hosted on a private server in a South African data centre. Once the responses were collected, they were exported in comma-separated values (CSV) format, which was then used by MATLAB to perform the required data conversions and calculations. MATLAB does not have built-in functionality for performing AHP analyses, and as such, custom code was developed. This functionality was tested against known data sets to ensure the validity of the results obtained through the custom toolkit.

\section{Limitations of analytical hierarchy process consistency}

Although Saaty (1990) provides a method for checking consistency of the results, this technique has been criticised by Alonso and Lamata (2006) as too restrictive when dealing with a large number of alternatives, or when combining decision matrices from a number of participants.

Based on the generation of 500000 random matrices, Alonso and Lamata (2006) propose a method of checking for consistency that does not utilise Saaty's technique, but instead uses $\lambda_{\max }$ and defines a general consistency condition, given by (Equation 1):

$$
\lambda_{\max } \leq n+\alpha(1.7699 n-4.3513) \quad \text { [Eqn 1] }
$$

Using this method, $n$ is the number of alternatives and $\alpha$ is the factor that defines the level of inconsistency that is 
tolerated (with $0<\alpha \leq 1$ ). For this research, it was found that $\lambda_{\max } \leq 0.2$ provided a good trade-off between consistency and the inclusion of sufficient decision matrices in the combined group decision. With these constraints, the final group decision could be determined by calculating the geometric mean of the individual matrices to obtain the group decision matrix. Once this had been calculated, the final results could be determined through a series of simple matrix calculations.

Having defined the research process, it was then executed to collect and analyse the data, with the results being presented in the next section.

\section{Research results \\ Participants' demographic profile}

Along with the ranking comparisons that each participant made, they were also asked to answer a series of demographic questions to establish an understanding of the small businesses that took part in the research.

Of the 44 responses that were received, the majority (58\%) were from businesses that operated with 1-5 employees, as shown in Figure 5, and only $11 \%$ of the businesses employed more than 20 people. Additionally, the data revealed that a quarter of the businesses operated entirely online, with the remainder relying on physical storefronts and office spaces (Figure 6). In all, 82\% of respondents were from the Johannesburg area, which highlights the relevance of this research to the City of Johannesburg. A total of $68 \%$ of the

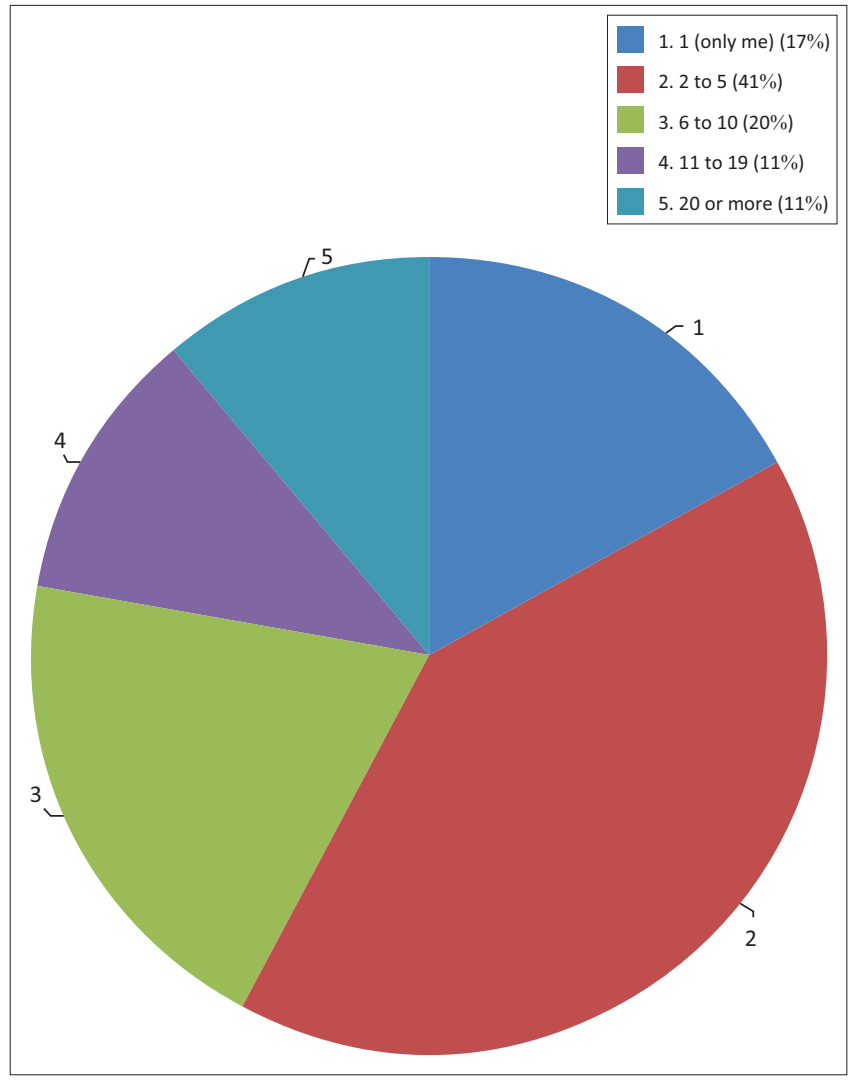

FIGURE 5: Participants by number of employees. participants operated within the engineering, consulting and construction sectors, while finance, insurance, real estate and education accounted for only $7 \%$ of the responses.

\section{Time and cost impact of small-business challenges}

To investigate the extent of triangulation, participants were required to answer several questions independently of the AHP comparisons. This was also used to confirm the findings in literature in respect of time lost and cost incurred when dealing with these challenges. Figure 7 shows a frequency distribution of the amount of time, in days, that each participant required to address each of the identified challenges on an annual basis. When considering the number of businesses that spent more than 20 days in dealing with any of the challenges, it becomes clear that these issues represent a significant amount of lost time to the businesses, with regulatory compliance being the biggest offender in this regard.

Figure 8 shows a frequency distribution of the amount of money, in rand, that each participant spent on each of the identified challenges on an annual basis. Of the 44 respondents, 10 indicated that infrastructure and workforce issues cost them over R100 000 per year, representing a serious cost that must be absorbed regularly. Although corruption was generally considered to not have much of an impact in terms of time, a quarter of the respondents reported that it cost them over R50 000 per year.

\section{Calculation of weighted rankings}

Following the process outlined by Saaty (2008), the pairwise comparisons from the questionnaire were converted to a total

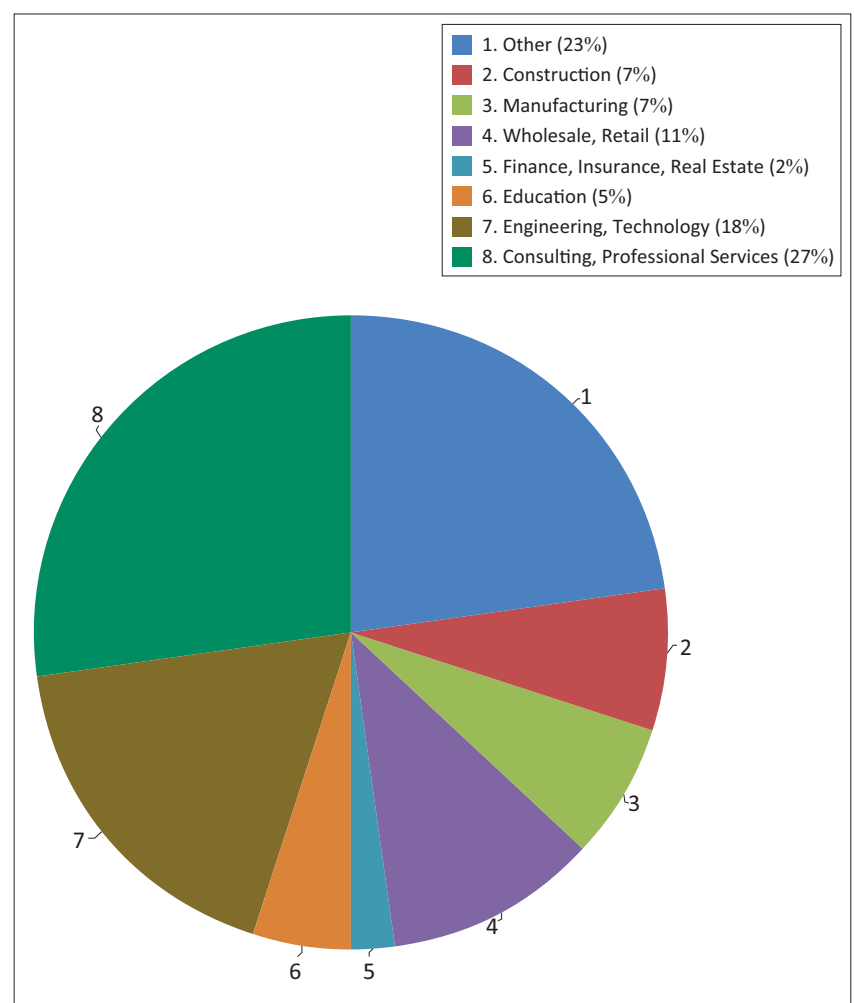

FIGURE 6: Participants by operational sector. 


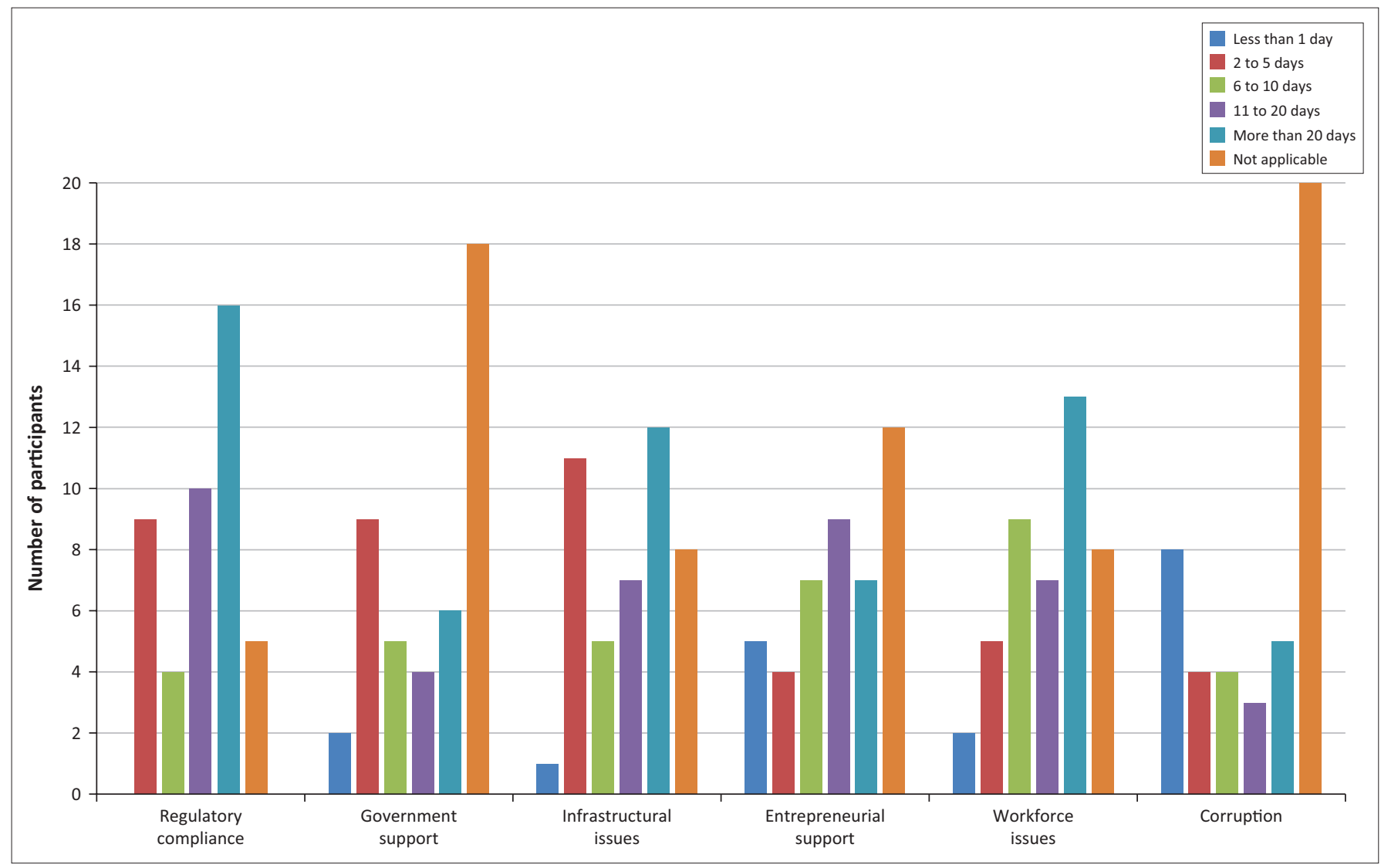

FIGURE 7: Time impact of the challenges faced on an annual basis.

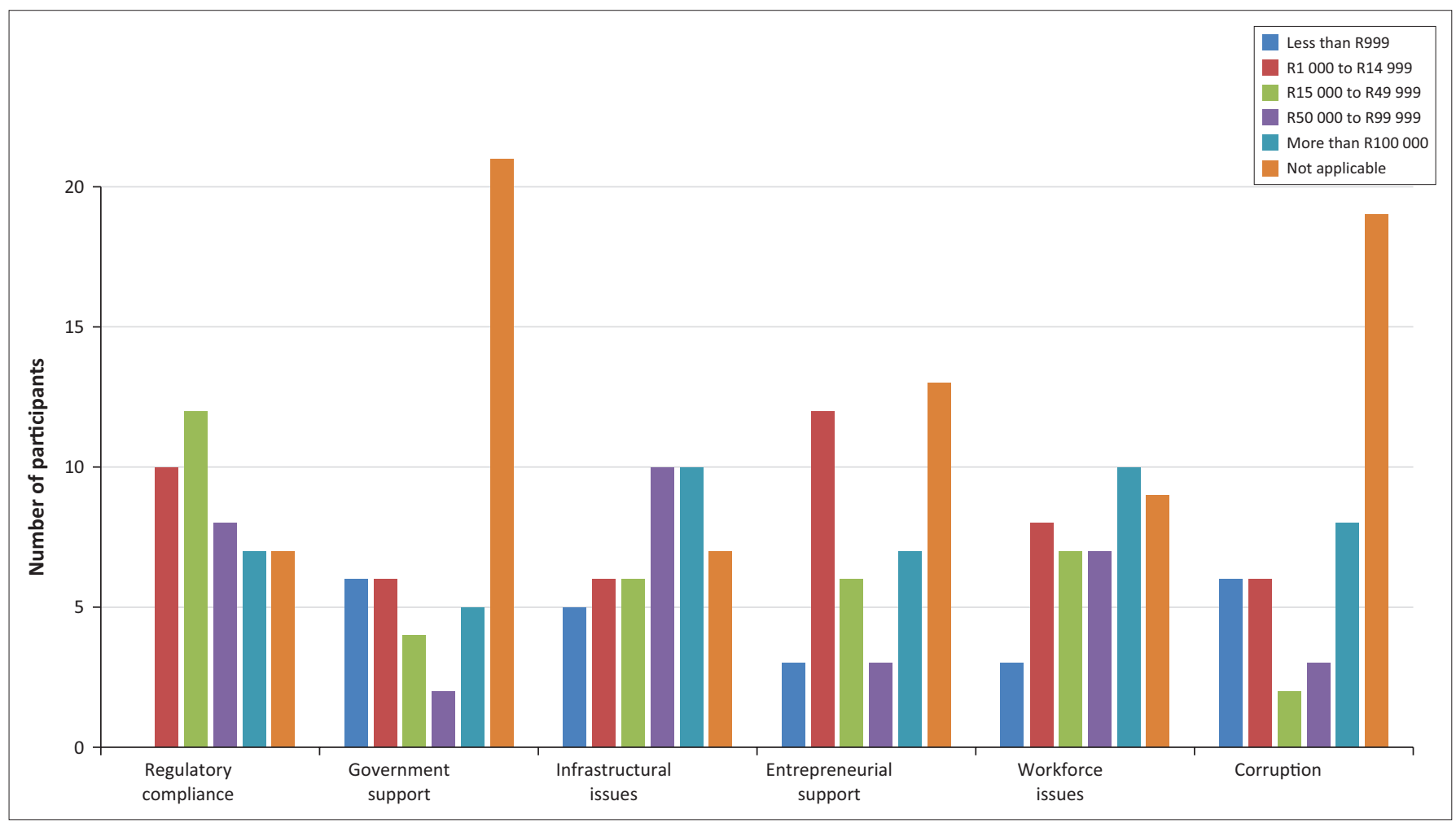

FIGURE 8: Annual cost impact because of challenges faced. 
of seven group decision matrices by calculating the geometric mean of the individual participant matrices. These seven matrices consist of:

- Challenge Time - the challenges faced with regard to the time impact on the business

- Challenge Cost - the challenges faced with regard to the cost impact on the business

- Cost Priority - the relative priorities of the criteria 'save time' and 'save money'

- Service Time - the smart city services with regard to the impact of time saved

- Service Cost - the smart city services in respect of the impact of cost saved

- Service Value - the smart city services in respect of the value and importance within a modern city

- Service Priority - the relative priorities of the criteria 'save time', 'save money' and 'importance in a modern city'.

To demonstrate, the matrix for the time impact of smallbusiness challenges was found to be (Equation 2):

Combined Challenge Time $=$

$\left(\begin{array}{llllll}1.0000 & 0.4502 & 0.9676 & 0.9471 & 1.1230 & 1.0721 \\ 2.2213 & 1.0000 & 1.7694 & 1.6572 & 1.9025 & 1.5614 \\ 1.0334 & 0.5652 & 1.0000 & 0.7723 & 1.2963 & 1.0488 \\ 1.0559 & 0.6034 & 1.2948 & 1.0000 & 1.1806 & 1.2510 \\ 0.8904 & 0.5256 & 0.7714 & 0.8470 & 1.0000 & 0.8973 \\ 0.9327 & 0.6404 & 0.9534 & 0.7994 & 1.1145 & 1.0000\end{array}\right)$ [Eqn 2]

The custom-developed MATLAB code was then used to determine the relative weightings of each challenge, as well as to perform consistency checking (Equation 3):

AHP $($ Combined Challenge Time $)=$

$\left[\begin{array}{l}0.1439 \\ 0.2655 \\ 0.1489 \\ 0.1671 \\ 0.1302 \\ 0.1444\end{array}\right]\left(\begin{array}{l}\text { Regulatory compliance } \\ \text { Govermment support } \\ \text { Infrastructural issues } \\ \text { Entreprenuerial suport } \\ \text { Workforce issues }\end{array}\right)$ [Eqn 3]

This process was repeated for each of the six remaining matrices, and the priorities of each alternative were overlaid on Figures 2 and 3 to yield Figures 9 and 10, respectively. These two figures show how the group decision was distributed across the various challenges and services. Within each block, the priority value indicates the relative importance of that item, with the sum of each group always being equal to 1 .

With these results, it is now possible to calculate the final priorities using matrix multiplication, in the form of $R=M \times P$, where $R$ is the vector of final normalised

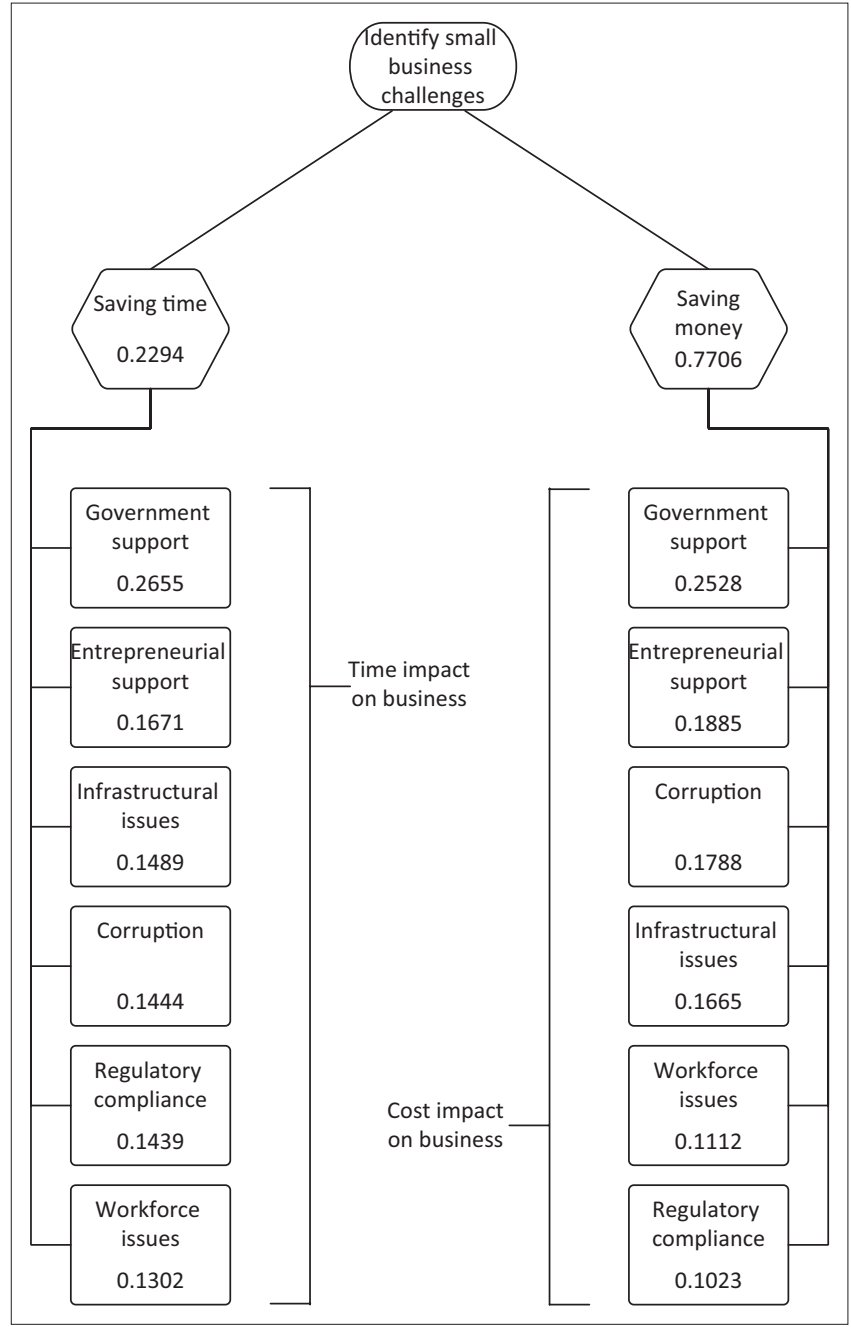

FIGURE 9: Relative impact of small-business challenges.

priorities, $M$ is the matrix of priorities of the various alternatives with regard to each criterion and $P$ is the vector of priorities for the criteria themselves. The calculation of these results is shown in Eqn 4 and Eqn 5.

$\begin{aligned} \text { Challenges } & =\left[\begin{array}{ll}0.1439 & 0.1023 \\ 0.2655 & 0.2528 \\ 0.1489 & 0.1665 \\ 0.1671 & 0.1885 \\ 0.1302 & 0.1112 \\ 0.1444 & 0.1788\end{array}\right] \times\left[\begin{array}{l}0.2294 \\ 0.7706\end{array}\right] \\ & =\left[\begin{array}{l}0.1118 \\ 0.2557 \\ 0.1625 \\ 0.1836 \\ 0.1156 \\ 0.1709\end{array}\right]\left(\begin{array}{l}\text { Regulatory compliance } \\ \text { Govermment support } \\ \text { Infrastructural issues } \\ \text { Entreprenuerial suport } \\ \text { Workforce issues } \\ \text { Corruption }\end{array}\right)\end{aligned}$

[Eqn 4]

Similarly, the final normalised priorities for smart city services can be calculated (Equation 5): 


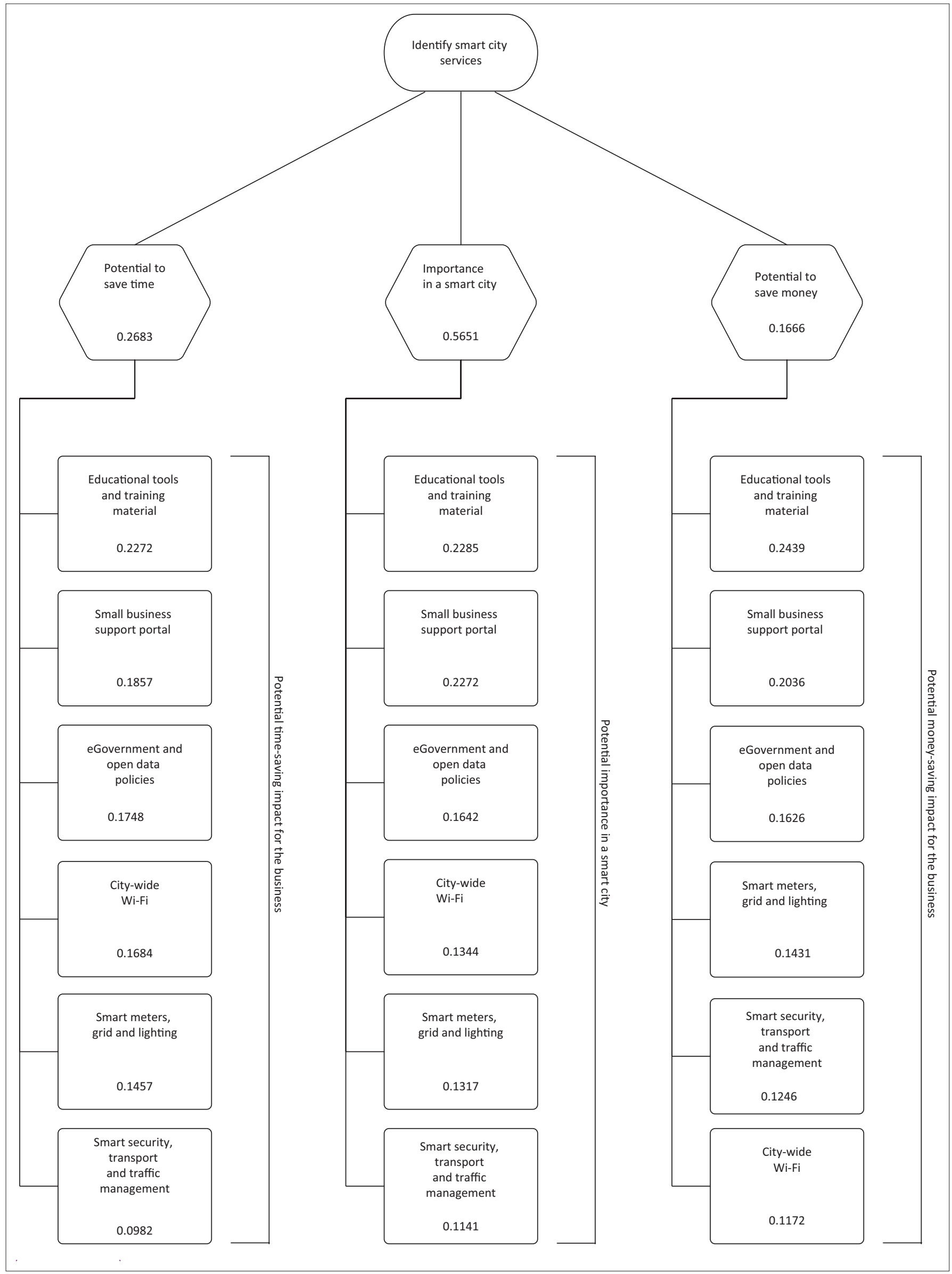

FIGURE 10: Relative value of smart city services. 
$\begin{aligned} \text { Services } & =\left[\begin{array}{lll}0.1684 & 0.1172 & 0.1344 \\ 0.1748 & 0.1626 & 0.1642 \\ 0.1857 & 0.2086 & 0.2272 \\ 0.1457 & 0.1431 & 0.1317 \\ 0.0982 & 0.1246 & 0.1141 \\ 0.2272 & 0.2439 & 0.2285\end{array}\right] \times\left[\begin{array}{l}0.2683 \\ 0.1666 \\ 0.5651\end{array}\right] \\ & =\left[\begin{array}{l}0.1407 \\ 0.1668 \\ 0.2130 \\ 0.1374 \\ 0.1115 \\ 0.2307\end{array}\right]\left(\begin{array}{l}\text { City-WideWi-Fi } \\ \text { eGovernment and open data policies } \\ \text { Small business support portal } \\ \text { Small meters, grid and lighting } \\ \text { Smart security, transport and traffic } \\ \text { Educational tools and training material }\end{array}\right)\end{aligned}$

[Eqn 5]

The results of the matrix multiplications in Equations 4 and 5 have been ordered by weighting and are presented in Table 3.

\section{Impact of small-business challenges and smart city services}

At this stage of the analysis, the results in Figure 9 show the clear preference of participants for saving money over saving time (77\% vs. $23 \%$ ), which highlights just how cash-sensitive small businesses are. Furthermore, Figure 9 shows that government support is the single largest factor and accounts for over a quarter of both the time and the cost impact, with entrepreneurial support being the second largest contributor in both time and cost impact.

Participants indicated that city-wide Wi-Fi deployment would have the lowest impact on their cost savings. This is surprising, as the cost of telecommunications was identified by Herrington et al. (2014) as one of the key factors that the South African government should work to reduce, and in doing so, alleviate some of the strain on small businesses.

While the participants did find it valuable if a smart city service was able to result in time and cost savings, the research revealed that the businesses placed strong emphasis (57\%) on a potential service's importance in a modern city, perhaps demonstrating the inherent interest that small businesses have in future developments. In this light, both educational tools and small-business portals were considered

TABLE 3: Weighted rankings of small-business challenges and smart city services.

\begin{tabular}{|c|c|c|c|c|}
\hline Rank & Priority (\%) & Challenge & Priority (\%) & Service \\
\hline 1 & 25.57 & $\begin{array}{l}\text { Government } \\
\text { support }\end{array}$ & 23.07 & $\begin{array}{l}\text { Educational tools and } \\
\text { training material }\end{array}$ \\
\hline 2 & 18.36 & $\begin{array}{l}\text { Entrepreneurial } \\
\text { support }\end{array}$ & 21.30 & $\begin{array}{l}\text { Small-business support } \\
\text { portal }\end{array}$ \\
\hline 3 & 17.09 & Corruption & 16.68 & $\begin{array}{l}\text { eGovernment and open } \\
\text { data policies }\end{array}$ \\
\hline 4 & 16.25 & $\begin{array}{l}\text { Infrastructural } \\
\text { issues }\end{array}$ & 14.07 & City-wide Wi-Fi \\
\hline 5 & 11.56 & Workforce issues & 13.74 & $\begin{array}{l}\text { Smart meters, grid and } \\
\text { lighting }\end{array}$ \\
\hline 6 & 11.18 & $\begin{array}{l}\text { Regulatory } \\
\text { compliance }\end{array}$ & 11.15 & $\begin{array}{l}\text { Smart security, transport } \\
\text { and traffic management }\end{array}$ \\
\hline
\end{tabular}

the most important aspects of a modern city, each accounting for over $22 \%$ of the weighting. Across the remaining two criteria, these two services were also the highest ranked.

Smart security and traffic management were generally regarded as unimportant $(<12 \%)$ across each of the three criteria, with slightly lower levels of disinterest $(<14 \%)$ being shown for services involving smart meters and power management.

While the impact of these challenges and services across the individual criteria does yield interesting perspectives, the true impact of these factors can be assessed when considering the final AHP-weighted priorities, as calculated previously using matrix multiplication.

\section{Ethical consideration}

The data collected have been kept confidential and only the aggregated and anonymised findings from the collected data were included in the publication.

\section{Discussion}

When considering the final weighted results, it becomes clear that government support dominates the challenges that are faced by small businesses, whereas educational tools and training material are deemed to be the most valuable.

Combined with the results presented in Table 2, the research shows a strong link between the services that were selected by the participants and the services that were identified through literature as being able to address these challenges. From the literature, it was also shown that the top three ranked services are, to some extent, capable of addressing each of the challenges that were identified. It is therefore imperative for any city to place a strong emphasis on these services to meet the needs of small businesses effectively.

These results confirm what was previously indicated by the literature - that the lack of government support constitutes the single greatest impact on the small businesses. This is followed closely by a lack of entrepreneurial support, corruption and infrastructural issues.

The results further show a clear preference for educational tools and training material - an aspect that was shown by Simpson, Tuck and Bellamy (2004) and Kangasharju and Pekkala (2001) as having a significant impact on the success of a business. In an ongoing effort to minimise costs and time wasted, especially because of the relatively small number of employees, it is understandable that small businesses wish to learn and explore on their own, a fact which is further supported by their interest in a small-business support portal and eGovernment and open data policies.

The analysis of the results has determined the extent to which the issues impact small businesses, but it will be the city's responsibility to subsequently implement the services. 
To ensure that this is successful, several prerequisites and dependencies must be considered during the smart city's development.

\section{Roadmap development}

Having identified the issues that need to be addressed, along with their relative importance, the infrastructural requirements can now be used to develop a smart city roadmap, shown in Figure 11, for the deployment of smart city services tailored towards supporting small businesses. Along the top of the roadmap, in green, are the challenges that businesses face, ordered by importance. Beneath that, in blue, is the ordered list of smart city services capable of addressing the challenges. These relationships were listed in Table 2 and are illustrated with a series of interconnecting lines. The $x$-axis shows the increasing integration that is required, and the $y$-axis shows the increasing levels of development. The relationships between the challenges and the services are also shown.

The deployed services would be heavily dependent on the use of ICT, and as such, care should be taken to ensure the stability, availability and resilience of the underlying infrastructure. Arana (2014) suggests that this could be accomplished through the use of an integration and monitoring layer, which would monitor the various systems in order to minimise the impact of subsystem failure. To protect the data, Arana (2014) further proposes that security and access control systems be implemented across the services.

With the basic infrastructure having been defined, the specific services can now be explored. Educational tools and training material were identified as being the most valuable, and the implementation of these services would provide support for entrepreneurs in multiple ways. At its simplest, this would require collaboration with educational institutions to make the relevant training available online.

Because of the limited resources that small businesses have, being able to leverage self-service systems was found to be highly valuable. Creating a central information repository and integrating it with other government departments would provide businesses with access to any required information and allow them to submit various documents electronically.

The small-business support portal would form the basis of a more complex eGovernment system, which would be expanded to include further integration with other

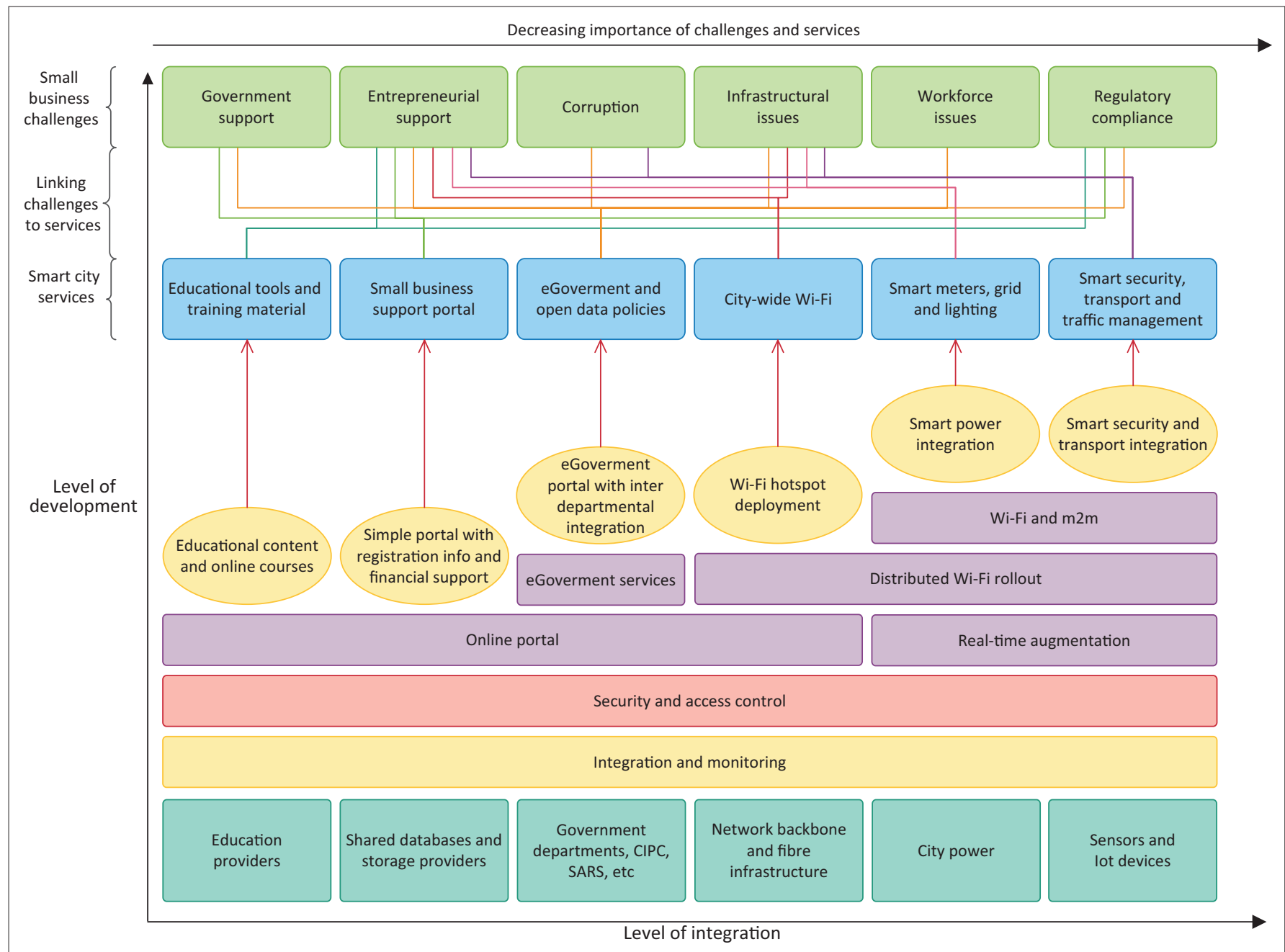

FIGURE 11: Proposed smart city roadmap for supporting small businesses. 
departments and third parties, thereby facilitating access to a variety of services in an effective and coherent manner. However, being able to offer these services would require increasing levels of development and integration, which can be a costly endeavour.

Thus far, all planned systems have relied on a centralised architecture. Before offering widespread Wi-Fi coverage, it is necessary to deploy infrastructure on a much wider scale. The deployment of city-wide fibre infrastructure will require extensive earthworks and construction and will be a timeconsuming process. It is therefore recommended that this phase be started in parallel with the initial smart city rollout. With this infrastructure in place, Wi-Fi hotspots can be deployed for use by stakeholders, as well as by connected sensor systems which provide data to the city.

The remaining services can be implemented through varying combinations of decentralised sensors and real-time monitoring systems to allow the city to optimise its efficiency and usage of resources.

If followed, the proposed roadmap will allow a city to implement the services that were found to be the most valuable to small businesses, in an order that would address their greatest challenges first. This infrastructure would then be used as a basis on which any number of additional services could be built.

\section{Limitations of this study and areas for further research}

Smart city development will affect many stakeholders within the city, and as such, it is crucial to ensure that all the stakeholders are considered before beginning the deployment process. This research covered a smart city's development from the perspective of small businesses, but other stakeholders, such as schools, communities, large businesses and even the government itself, would need to be considered.

It was also discovered that some individual decision matrices needed to be discarded as they failed to meet the consistency restrictions set during the research design. To alleviate this, it is suggested that future survey methods incorporate realtime feedback to the participants, so that they can correct inconsistent responses, thereby ensuring that all the decision matrices can be used to form the group decision.

SEDA (2016) found that there are 667433 formal SMEs in South Africa, meaning that this research was conducted with a very small sample size. Although this research could provide initial insight into the challenges faced, it is recommended that further research with a larger sample be carried out in future. These results cannot be generalised to all small businesses within South Africa, as they were obtained from a limited subset of the target research population. However, because of the shortage of research linking smart cities and small businesses, the results of this research can be used as a basis for planning future research.

\section{Conclusions}

This research set out to identify the challenges faced by small businesses and then explored which smart city services, if any, would be able to address these challenges. An initial literature survey was used to identify potential challenges and services, with this knowledge being used to guide the design of the research instrument.

The AHP was identified as a suitable methodology because of its ability to make group decisions based on both subjective and objective judgements to obtain a single, coherent decision. This approach yielded a final set of ranked priorities, showing the relative importance of each alternative.

This research sought to identify which challenges had the greatest impact on small businesses. The lack of government support was found to be the most detrimental. Similarly, the research sought to identify which smart city services offered the most value, and it was found that educational tools and training material would assist the most in addressing the challenges that are constantly faced. The literature was used to derive a link between the services and the challenges they could potentially address. These findings were supported by the research participants by identifying which services they found to be the most valuable.

In terms of time lost and cost incurred, both the literature and the research demonstrated that these challenges have a substantial impact on small businesses, with businesses spending weeks of time and hundreds of thousands of rand to address the challenges. By developing solutions and systems to minimise the impact of these challenges, cities would be able to provide direct value to the businesses, allowing them to save both time and money and thereby increasing their chances of success.

Finally, this research intended to use these findings to develop a smart city roadmap focused on alleviating the challenges faced by small businesses. Cities following the roadmap's recommendations would be able to quickly and effectively deploy the required infrastructure and integrations needed to start offering these services. This would allow small businesses to waste less of their resources in dealing with these challenges, and instead focus on what they do best driving employment and contributing to the economy.

\section{Acknowledgements Competing interests}

The authors declare that they have no financial or personal relationships that may have inappropriately influenced them in writing this article.

\section{Authors' contributions}

The research focus and methodology was planned by all authors, with the data collection being conducted, compiled 
and analysed by H.d.P. All authors then drew conclusions and made further recommendations.

\section{References}

Adisa, T.A., Abdulraheem, I. \& Mordi, C., 2014, 'The characteristics and challenges of small businesses in Africa: An exploratory study of Nigerian small business owners', Economic Insights - Trends and Challenges 3(4), 1-14.

Albino, V., Berardi, U. \& Dangelico, R.M., 2015, 'Smart cities: Definitions, dimensions, performance, and initiatives', Journal of Urban Technology 22(1), 3-21. https:// doi.org/10.1080/10630732.2014.942092

Alonso, J. \& Lamata, M., 2006, 'Consistency in the analytical hierarchy process: A new approach', International Journal of Uncertainty, Fuzziness and Knowledge-Based Systems 14(4), 445-459. https://doi.org/10.1142/S0218488506004114

Andersen, T.B., 2009, 'E-government as an anti-corruption strategy', Information Economics and Policy 21(3), 201-210. https://doi.org/10.1016/j.infoecopol. 2008.11.003

Arana, S., 2014, Smart sustainable cities - A road map, viewed 29 April 2016, from https://itunews.itu.int/En/5217-Smart-sustainable-cities-a-road-map.note.aspx

Bătăgan, L., 2011, 'Smart cities and sustainability models', Revista de Informatică Economică 15(3), 80-87, viewed 06 June 2017, from http://revistaie.ase.ro/ content/59/07-Batagan.pdf

Bradley, J., Barbier, J. \& Handler, D., 2013, Embracing the internet of everything to capture your share of \$14.4 trillion, viewed 06 June 2017, from http://www.cisco. com/web/about/ac79/docs/innov/loE_Economy.pdf

Branchi, P., Fernández-Valdivielso, C. \& Matias, I., 2014, 'Analysis matrix for smart cities', Future Internet 6(1), 61-75. https://doi.org/10.3390/fi6010061

Brunelli, M., 2015, Introduction to the analytic hierarchy process, Springer International Publishing (Springer Briefs in Operations Research), Cham. https:// doi.org/10.1007/978-3-319-12502-2

Burger, S., 2015, Joburg opens smart city portal to smaller municipalities, viewed 12 May 2016, from http://m.engineeringnews.co.za/article/city-of-johannesburgopens-smart-city-portal-to-smaller-municipalities-2015-04-17

Calderoni, L., Maio, D. \& Palmieri, P., 2012, 'Location-aware mobile services for a smart city: Design, implementation and deployment', Journal of Theoretical and Applied Electronic Commerce Research 7(3), 15-16. https://doi.org/10.4067/ Applied Electronic Commer

Calzada, I. \& Cobo, C., 2015, 'Unplugging: Deconstructing the smart city', Journal of Urban Technology 22(1), 23-43. https://doi.org/10.1080/10630732.2014.971535

Caragliu, A., Del Bo, C. \& Nijkamp, P., 2011, 'Smart cities in Europe', Journal of Urban Technology 18(2), 65-82. https://doi.org/10.1080/10630732.2011.601117

Castillo, M., 2013 'The wisdom of crowds', American Journal of Neuroradiology 34(10), 1863-1865. https://doi.org/10.3174/ajnr.A3417

Chen, Y.K., Jaw, Y.-L. \& Wu, B.-L., 2016, 'Effect of digital transformation on organisational performance of SMEs', Internet Research 26(1), 186-212. https://doi.org/10.1108/ IntR-12-2013-0265

Chourabi, H., Nam, T., Walker, S., Gil-Garcia, J.R., Mellouli, S., Nahon, K. et al., 2012 'Understanding smart cities: An integrative framework', in 2012 45th Hawail International Conference on System Sciences, IEEE, Maui, HI, January 4-7, 2012 pp. 2289-2297.

Dirks, S. \& Keeling, M., 2009, A vision of smarter cities, viewed 06 June 2017, from http://www-935.ibm.com/services/us/gbs/bus/pdf/ibm_podcast_smarter cities.pdf

Groepe, F., 2012, The role of business in the national development plan, Bank for International Settlements, Johannesburg, viewed 06 June 2017, from http://www. bis.org/review/r121022b.pdf

Herrington, M., Kew, J. \& Kew, P., 2010, GEM South Africa 2010 report, global entrepreneurship monitor, Global Entrepreneurship Monitor Consortium, Cape Town.

Herrington, M., Kew, J. \& Kew, P., 2014, GEM South Africa report, Cape Town, viewed 06 June 2017, from http://gemconsortium.org/report/48359

Hong Kong Government, 2016, Government backbone network, viewed 27 April 2016 , from http://www.ogcio.gov.hk/en/infrastructure/e_government/gnet/ government_backbone_network.htm

Kakderi, C., 2014, Birmingham's smart city roadmap, urban and regional innovation research, viewed 29 April 2016, from http://www.urenio.org/2014/03/04/ birminghams-smart-city-roadmap/

Kangasharju, A. \& Pekkala, S., 2001, The role of education in self-employment success, viewed 06 June 2017, from ftp://ftp.kent.ac.uk/pub/ejr/RePEc/ukc/ukcedp/0116. pdf

Kirkwood, J., Dwyer, K. \& Gray, B., 2014, 'Students' reflections on the value of an entrepreneurship education', The International Journal of Management Education 12(3), 307-316. https://doi.org/10.1016/j.ijme.2014.07.005

Kuk, G. \& Janssen, M., 2011, 'The business models and information architectures of smart cities', Journal of Urban Technology 18(2), 39-52. https://doi.org/10.1080/ 10630732.2011.601109

Kumar, T.M.V., 2015, 'E-governance for smart cities', in T.M. Vinod Kumar (ed.) E-governance for smart cities, Advances in 21st Century Human Settlements, pp. 373-383, Springer, Singapore. https://doi.org/10.1007/978-981-287-287-6
Lee, J., 2010, Barack Obama: Of governments, business, and jobs, viewed 12 May 2016, from https://www.whitehouse.gov/blog/2010/02/24/governmentbusiness-jobs

Lee, J.H., Hancock, M.G. \& Hu, M., 2014, 'Towards an effective framework for building smart cities: Lessons from Seoul and San Francisco', Technological Forecasting and Social Change 89, 80-99. https://doi.org/10.1016/j.techfore.2013.08.033 Lee, J.H., Phaal, R. \& Lee, S.-H., 2013, 'An integrated service-device-technology
roadmap for smart city development', Technological Forecasting and Social Change 80(2), 286-306. https://doi.org/10.1016/j.techfore.2012.09.020

Letaifa, S., 2015, 'How to strategize smart cities: Revealing the SMART model', Journa of Business Research 68(7), 1414-1419. https://doi.org/10.1016/j.jbusres. 2015.01.024

Lio, M., Liu, M. \& Ou, Y., 2011, 'Can the internet reduce corruption? A cross-country study based on dynamic panel data models', Government Information Quarterly 28(1), 47-53. https://doi.org/10.1016/j.giq.2010.01.005

Lövehagen, N. \& Bondesson, A., 2013, 'Evaluating sustainability of using ICT solutions in smart cities - Methodology requirements', in International Conference on Information and Communication Technologies for Sustainability, Zurich, February 14-16, 2013, pp. 175-182.

National Planning Commission, 2010, National development plan (2030), Nationa Planning Commission, Pretoria, South Africa.

Neupane, A., Soar, J., Vaidya, K. \& Yong, J., 2014, 'Willingness to adopt e-procurement to reduce corruption', Transforming Government: People, Process and Policy 8(4), 500-520. https://doi.org/10.1108/TG-03-2014-0007

New Zealand Government, 2015, Small businesses in New Zealand, viewed 06 June 2017, from http://www.mbie.govt.nz/info-services/business/business-growthagenda/sectors-reports-series/the-small-business-sector-report-and-factsheet

Olawale, F. \& Garwe, D., 2010, 'Obstacles to the growth of new SMEs in South Africa: A principal component analysis approach', African Journal of Business Management 4(5), 729-738.

Peniwati, K., 2007, 'Criteria for evaluating group decision-making methods' Mathematical and Computer Modelling 46(7-8), 935-947. https://doi.org/ 10.1016/j.mcm.2007.03.005

Peters, R. \& Naicker, V., 2013, 'Small medium micro enterprise business goals and government support: A South African case study', South African Journal of Business Management 44(4), 13-24.

Ryan, O., 2014, Building the infrastructure for eGovernment, Reach Agency, Ireland. https://doi.org/10.1007/978-1-4302-6146-9

Saaty, R.W., 1987, 'The analytic hierarchy process - What it is and how it is used' Mathematical Modelling 9(3-5), 161-176. https://doi.org/10.1016/02700255(87)90473-8

Saaty, T.L., 1990, 'How to make a decision: The analytic hierarchy process', European Journal of Operational Research 48(1), 9-26. https://doi.org/10.1016/03772217(90)90057-1

Saaty, T.L., 2008, 'Decision making with the analytic hierarchy process', International Journal of Services Sciences 1(1), 83. https://doi.org/10.1504/IJSSCI.2008.017590

SBP, 2004, Counting the cost of red tape, Small Business Project, Johannesburg, South Africa.

SBP, 2014, Examining the challenges facing small businesses in South Africa, viewed 06 June 2017, from http://www.sbp.org.za/uploads/media/SBP_Alert_Examining_the_challenges_facing_small_businesses_in_SA_01.pdf

Schwab, K., 2014, The global competitiveness report 2014-2015, viewed 07 May 2016, from http://www.weforum.org/pdf/Global_Competitiveness_Reports/ Reports/factsheet_gcr03.pdf

SEDA, 2016, The small, medium and micro enterprise sector of South Africa, viewed 06 June 2017, from http://www.seda.org.za/Publications/Publications/The Small, Medium and Micro Enterprise Sector of South Africa Commissioned by Seda.pdf

Shezi, L., 2015, Online varsity to give Joburg residents free access to recognised courses, htxt.africa, viewed 05 May 2016, from http://www.htxt.co. za/2015/05/06/online-varsity-to-give-joburg-residents-free-access-torecognised-courses/

Simpson, M., Tuck, N. \& Bellamy, S., 2004, 'Small business success factors: The role of education and training', Education + Training 46(8/9), 481-491. https://doi. org/10.1108/00400910410569605

Stratigea, A., Papadopoulou, C.-A. \& Panagiotopoulou, M., 2015, 'Tools and technologies for planning the development of smart cities', Journal of Urban Technology 22(2), 43-62. https://doi.org/10.1080/10630732.2015.1018725

Templeton, A., 2015, Joburg gets started on its smart city vision, viewed 07 May 2016, from http://www.moneyweb.co.za/news/south-africa/joburg-gets-started-onits-smart-city-vision-2/

The World Bank, 2011, 'Improving the business environment for growth and job creation in South Africa: The second investment climate assessment', (October) viewed 06 June 2017, from http://documents.worldbank.org/curated/ en/2011/10/16376800/south-africa-improving-business-environment-growthjob-creation-south-africa-second-investment-climate-assessment

United Nations, 2014, United Nations E-Government Survey 2014 'E-Government for the future we want', viewed 06 June 2017, from http://unpan3.un.org/egovkb/ Portals/egovkb/Documents/un/2014-Survey/E-Gov_Complete_Survey-2014.pdf

Vaidya, O.S. \& Kumar, S., 2006, 'Analytic hierarchy process: An overview of applications', European Journal of Operational Research 169(1), 1-29. https://doi. org/10.1016/j.ejor.2004.04.028 
Walravens, N., 2015, 'Mobile city applications for Brussels citizens: Smart city trends, challenges and a reality check', Telematics and Informatics 32(2), 282-299. https://doi.org/10.1016/j.tele.2014.09.004

Wang, S. \& Wang, H., 2015, 'Design and delivery of a new course of information technology for small business', Journal of Information Systems Education 26(1), 37-47.

Woods, E. \& Goldstein, N., 2014, 'Navigant research Leaderboard report: Smart city suppliers. Assessment of strategy and execution for 15 smart city suppliers', p. 53, viewed 12 March 2016, from http://www.ibm.com/smarterplanet/global/files/ us en us smarter cities navigant research report.pdf
Worku, Z., 2016, 'Barriers to the growth of small, micro and medium-sized business enterprises in the Vaal Triangle region of South Africa', African Journal of Science, Technology, Innovation and Development, 8(2), 134-141. https://doi.org/10.1080 /20421338.2015.1128135

World Bank Group, 2014, Doing business 2015: Going beyond efficiency, Washington, DC. https://doi.org/10.1596/978-1-4648-0351-2

Zulu, L., 2015, Importance of SMMEs is big business for country, viewed 12 January 2016, from http://www.iol.co.za/business/opinion/importance-of-smmes-is-bigbusiness-for-country-1.1768670?noredirect\#.Vgehwl-qpBc 


\section{Appendix 1}

Table 1-A1 lists the definitions of terms used throughout this research. These definitions were also supplied to the research participants when completing questionnaires.

TABLE 1-A1: Definitions of terms used throughout the article.

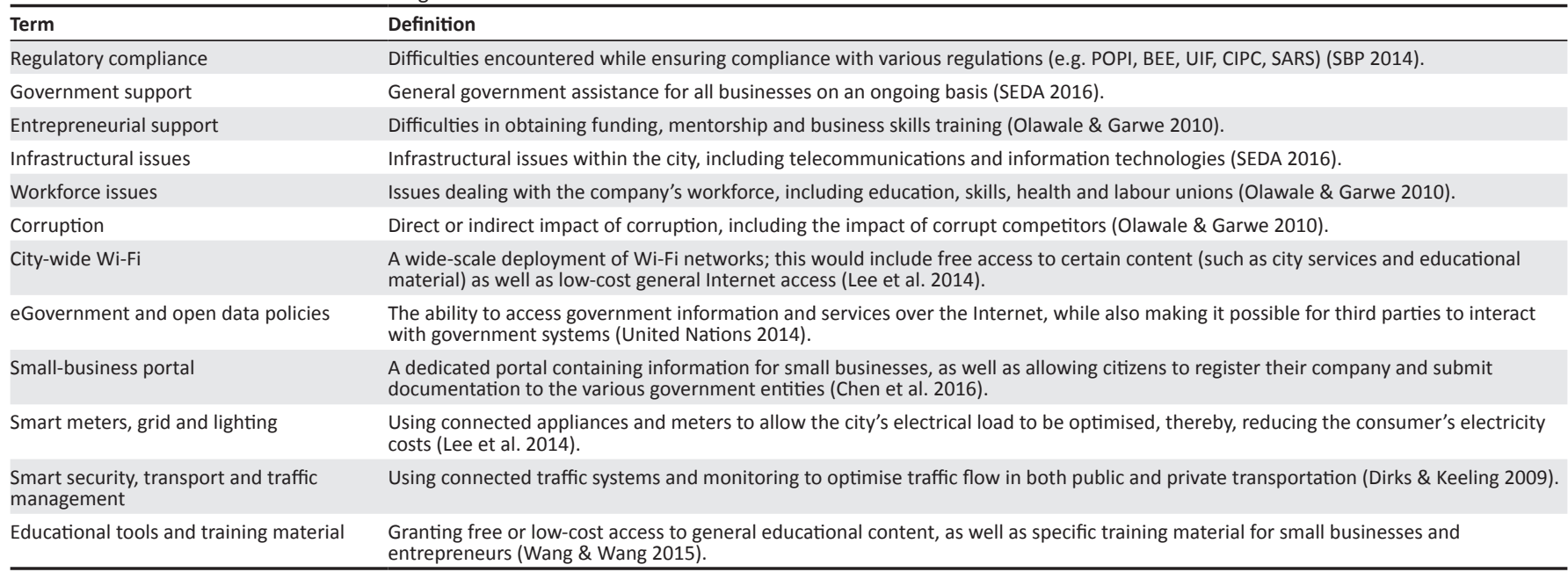

